\title{
Reconstrução uretral com retalho autógeno de mucosa bucal após uretrostomia, em cães ${ }^{1}$
}

\author{
Neusa Margarida Paulo ${ }^{2}$, Fernando Ferro da Silva ${ }^{3}$, George Alves de Brito ${ }^{4}$, Adilson Donizeti Damasceno, \\ Luiz Augusto Batista Brito ${ }^{6}$, José de Souza Freitas ${ }^{7}$, Patrícia Lorena Neves ${ }^{8}$, Maira Harumi Akinaga ${ }^{9}$, \\ Lorena Magalhães Barbosa ${ }^{9}$, Cleizony Morais Vêncio ${ }^{4}$
}

\begin{abstract}
Paulo NM, Silva FF, Brito GA, Damasceno AD, Brito LAB, Freitas JS, Neves PL, Akinaga MH, Barbosa LM, Vêncio CM. Reconstrução uretral com retalho autógeno de mucosa bucal após uretrostomia, em cães. Acta Cir Bras [serial online] 2004 Mar-Abr;19(2). Disponível em URL: http://www.scielo.br/acb
\end{abstract}

RESUMO - Objetivo: Verificar se fragmentos de mucosa bucal autógena poderiam ser adequados para reconstrução uretral na presença de tecido fibroso, e se tal procedimento poderia determinar a formação de fístulas e ou saculações nos sítios implantares. Métodos: Sete cães adultos foram submetidos à uretrostomia pré-escrotal. Após 40 dias, a uretrostomia foi corrigida por meio da implantação de fragmentos de mucosa bucal na parede ventral da uretra. Os animais foram observados durante 40 dias, quando então, foram submetidos a exames radiográficos e sacrificados para estudo histológico. Resultados: Todos os animais apresentaram cistite e fístulas uretro-cutâneas de duração média de vinte dias foram observadas em seis deles. $\mathrm{O}$ aspecto radiográfico aos 40 dias após a reconstrução uretral mostrou: continuidade luminal em sete animais e presença de saculações na parede ventral da uretra em seis, sem interferência na qualidade do jato urinário. As características histológicas indicam integração completa da mucosa bucal ao sítio receptor. Conclusão: O implante em retalho ventral, com fragmentos de mucosa bucal autógena é adequado para correção de defeito uretral produzido por uretrostomia no cão embora possa ocorrer a formação de saculações no sítio do selamento.

DESCRITORES - Cães. Mucosa bucal. Transplante homólogo. Uretra.

\section{Introdução}

As afecções uretrais que exigem reconstrução vão variar conforme a espécie abordada. No homem, defeitos uretrais congênitos ou adquiridos, representam um grave problema se a lesão é longa ou se há insuficiente pele prepucial disponível para enxerto, ou ainda se procedimentos cirúrgicos uretrais precedentes foram realizados. Neste último caso, a pele genital se apresenta fibrosada e insuficientemente vascularizada, o que resulta em alta incidência de complicações pós-operatórias. ${ }^{1,2}$ Além disto, a pele extra-genital apresenta uma grossa camada dermal ${ }^{3,4} \mathrm{e}$ o fracasso decorrente da utilização desse tecido ocorre em função de sua alta tendência à contração, principalmente nos casos de enxertos de espessura total. Pacientes que requerem reconstrução uretral, mas que possuem pouca disponibilidade de tecido genital são considerados grandes desafios técnicos para os cirurgiões urológicos. A uretroplastia com o emprego da mucosa bucal tem representado alternativa mais adequada para substituição do tecido lesado por um retalho de material adequado para restaurar o calibre da uretra normal ${ }^{4}$.
Na prática veterinária de pequenos animais, os profissionais são freqüentemente confrontados com pacientes que sofrem lesões traumáticas do trato urinário decorrentes de diferentes causas. Rupturas uretrais no cão são, em ordem de ocorrência, somente inferiores às rupturas renais ${ }^{5}$. Para esta espécie, as complicações mais comuns decorrentes do reparo de ferimentos uretrais são formação de estenose e extravasamento urinário ${ }^{6}$.

Uma importante possibilidade a ser considerada após a uretrostomia no cão é o aumento da predisposição às infecções vesicais, comprometendo o prognóstico

\footnotetext{
1. Trabalho realizado no Setor de Cirurgia do Hospital Veterinário da Escola de Veterinária (EV) da Universidade Federal de Goiás (UFG).

2. Professora Adjunto, Doutora - Setor de Clinica e Cirurgia da EV-UFG.

3. Médico Urologista - Santa Casa de Misericórdia de Goiânia.

4. Médico Residente em Urologia - Santa Casa de Misericórdia de Goiânia.

5. Doutorando em Ciência Animal - EV-UFG.

6. Professor Titular Doutor - Setor Patologia Animal da EV-UFG.

7. Professor Titular de Radiologia Veterinária da EV-UFG.

8. Mestre, Médica Veterinária Hospital Veterinário da EV-UFG.

9. Acadêmicas do Curso de Medicina Veterinária da EV-UFG.
} 
$\operatorname{tardio}^{7}$. A quebra da integridade das barreiras anatômicas de defesa implica no acesso de bactérias ao trato urinário. Assim, defeitos anatômicos adquiridos, como as uretrostomias representam uma importante etiologia das infecções complicadas do trato urinário de cães e gatos ${ }^{8}$.

A mucosa bucal como material para uretroplastia de substituição tem sido largamente sugerida, ${ }^{9,11,12}$. Este material apresenta condições metabólicas favoráveis que permitem a sua utilização sobre tecidos fibrosados e mal vascularizados, apresentando ainda alta resistência aos traumatismos e às infecções ${ }^{13}$. Outros fatores como, facilidade de obtenção e ausência de pelos são considerados determinantes para o sucesso da implantação da mucosa bucal ${ }^{3}$

Tem-se sugerido que a técnica de uretroplastia com mucosa bucal no homem tem a tendência a aumentar o tempo operatório. Assim para minimizar tal problema, considera-se necessário que duas equipes trabalhem simultaneamente; uma se encarrega de expor e calibrar a uretra enquanto outra promove a retirada do fragmento de mucosa bucal. Além deste aspecto, pode ser observado que em situações clínicas, os enxertos dorsais em retalho na uretra humana, apresentam vantagens em relação àqueles fixados ventralmente, uma vez que são evitadas as saculações ventrais e são limitadas as formações de fístulas ${ }^{14}$.

$\mathrm{O}$ grande mérito da mucosa bucal sobre os demais implantes é o fato deste material apresentar abundante elastina, o que o torna resistente. Ainda deve-se considerar que a rica vascularização de sua camada submucosa promove a rápida neovascularização do implante ${ }^{15}$. A escolha entre um implante em formato de tubo ou em retalho é dependente da característica do defeito uretral. Em geral, os enxertos tubulares são eleitos para correção de hipospadias, enquanto que para os demais casos, prefere-se os enxertos em retalho ${ }^{3}$.

A execução deste experimento visou principalmente verificar se fragmentos de mucosa bucal autógena poderiam ser adequados para reconstrução uretral na presença de tecido fibroso, e se tal procedimento poderia determinar a formação de fístulas e ou saculações nos sítios implantares. Propôs-se ainda o envolvimento interprofissional entre a Medicina Humana e Medicina Veterinária na busca da resolução de problemas similares entre os seus diferentes pacientes.

\section{Métodos}

Foram utilizados sete cães adultos, com peso variando entre 10 a $15 \mathrm{~kg}$ e sem alterações clínicas conforme verificado por meio de exames pré-operatórios. Durante este experimento, os animais foram mantidos em gaiolas individuais, com água e comida ad libitum. Todas as etapas deste experimento obedeceram aos critérios éticos sugeridos no Brasil pelo COBEA (Colégio Brasileiro de Experimentação Animal), para uso de animais em experimentação ${ }^{16}$. Os cães foram pré-anestesiados com clorpromazina ( $1 \mathrm{mg} / \mathrm{kg}$ IV) e a indução e manutenção anestésica foi por meio da administração de tiopental sódico (15 mg/kg IV).

Os procedimentos cirúrgicos foram realizados em duas etapas:

$1^{\text {a }}$ - Realização da uretrostomia. Os animais tiveram suas uretras cateterizadas com sonda descartável siliconizada. Auretra préescrotal foi exposta e seccionada longitudinalmente. Em seguida procedeu-se a sutura de suas bordas na pele empregando fio de poliéster 3-0 em padrão simples separado. Ao término do procedimento a sonda foi cortada rente à glande e suturada nesta com um ponto de fio poliéster 2-0. Os animais portaram colares elizabetanos durante sete dias. O resultado deste procedimento aos 40 dias do pós-operatório pode ser visualizado na Figura 1A.

$2^{\mathrm{a}}$ - Realização da uretroplastia. Este procedimento foi realizado ao final do $40^{\circ}$ dia de pós-operatório, sendo procedido em duas fases simultâneas; a primeira considerada como fase uretral e a segunda como fase bucal. Os animais tiveram suas uretras cateterizadas e os tecidos peri-uretrais e cicatriciais foram dissecados e removidos até que as bordas uretrais ficassem evidentes. Para facilitar a delimitação e remoção de um fragmento de mucosa bucal, aplicou-se quatro pontos de reparo no lábio superior, e com o auxílio do bisturi desenhou-se um retângulo entre estes. Uma tesoura fina foi utilizada para dissecar o tecido submucoso de forma que o fragmento ficasse o mais fino possível. Uma vez removidos, os fragmentos eram imersos em solução de cloreto de sódio a $0,9 \%$ enquanto se procedia a sutura da ferida bucal com fio de poliester 4-0. Em seguida produziuse retalhos elípticos de mucosa bucal, os quais foram suturados às bordas do defeito uretral em padrão simples interrompido empregando fio categute cromado 4-0 (agu- lha $1,5 \mathrm{~cm})$. A fixação da sonda uretral e as medidas de prevenção da auto-mutilação foram realizadas conforme descrito para a primeira etapa.

Em ambas as etapas o protocolo medicamentoso adotado no pós-operatório consistiu da administração de enrofloxacina $(5 \mathrm{mg} / \mathrm{kg}$, SID, IM) durante oito dias e flunixin meglumine ( $1 \mathrm{mg} / \mathrm{kg}$, SID, IM) por cinco dias. Aos 40 dias da segunda etapa, os animais tiveram suas uretras radiografadas por meio de uretrografia contrastada retrógrada utilizando diatrizoato de meglumina e sódio. Após este procedimento, ainda sob anestesia geral barbitúrica, os animais foram sacrificados.

Durante a necropsia procedeu-se ao exame macroscópico do sistema urinário e dos sítios implantares, dos quais foram coletados fragmentos que em seguida foram fixados em formalina tamponada neutra a $10 \%$ e processados conforme rotina de inclusão em parafina. O material foi seccionado em micrótomo rotativo a $5 \mu \mathrm{m}$ e corados de acordo com a técnica de rotina de hematoxilina e eosina e observados em microscópio óptico de campo claro.

\section{Resultados}

Todos os animais tiveram evolução satisfatória, observando-se apenas sangramento pós-cirúrgico dentro da primeira semana do pós-operatório.

A ressecção do fragmento de mucosa bucal do lábio superior foi uma manobra simples e rápida. Eventuais sangramentos foram resolvidos por meio de compressão digital. Todos os animais puderam se alimentar livremente no dia seguinte aos procedimentos.

As sondas uretrais inicialmente estavam previstas para permancer in situ durante cinco dias em ambas etapas. Entretanto, em todos os animais houve perda das mesmas até o terceiro dia pós-operatório.

No exame anatomopatológico foi observado cistite caracterizada por intensa neovascularização e espessamento da parede vesical, em todos os cães avaliados.

O aspecto radiográfico, aos 40 dias após a reconstrução uretral, mostrou: continuidade luminal (Figura 2A) em sete animais com presença de saculações na parede ventral da uretra (Figura 2B) em seis. As alterações anatômicas não interferiram na qualidade do jato urinário.

As características histológicas corroboraram para a integração completa da mucosa 
bucal ao sítio receptor. De modo geral, observou-se um epitélio de transição característico, sem resquícios da arquitetura original da mucosa bucal (Figura 3A e B). A área sub-epidérmica caracterizou-se pela presença de edema e grande quantidade de brotos vasculares, alguns inclusive preenchidos por hemácias, indicando formação de tecido de granulação (Figura 2C). Observou-se ainda infiltrado linfo- plasmocitário de grau variado, que sugere processo crônico evoluindo para a recuperação do tecido (Figura 3D). Neutrófilos foram observados eventualmente.
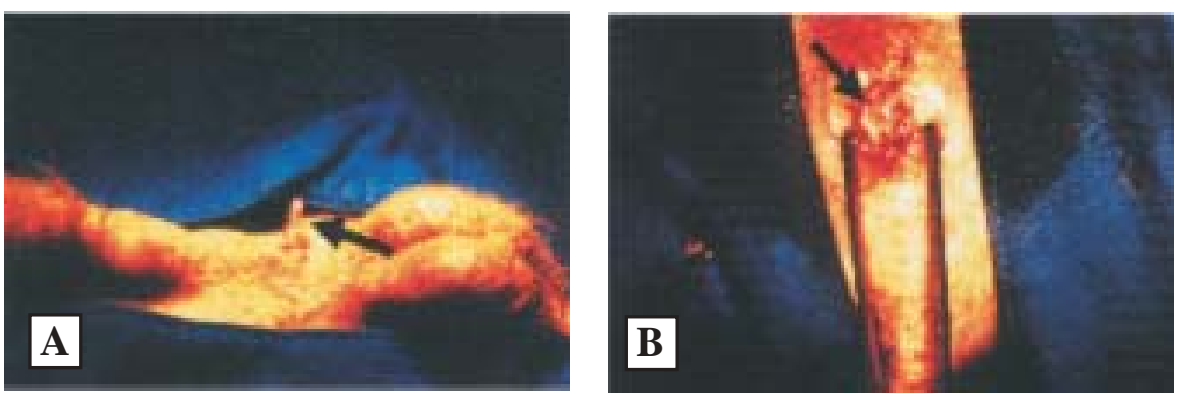

FIGURA 1 - Aspecto da uretrostomia aos 40 dias de pós-operatório, evidenciada pela exposição de sonda uretral pela fístula (A/seta). Retalho elíptico de mucosa bucal suturado às bordas do defeito uretral em padrão simples interrompido (B/seta).
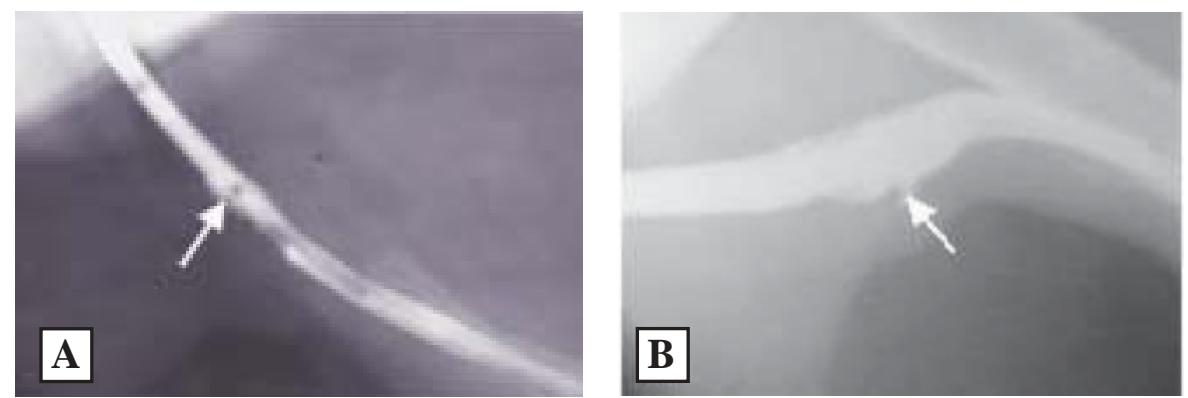

FIGURA 2 - Aspecto radiográfico da uretra peniana de cão submetida a reconstrução de sua parede ventral com fragmentos de mucosa bucal aos 40 dias de pós-operatório, evidenciando continuidade luminal (A/seta) e saculações ventrais (B/seta).
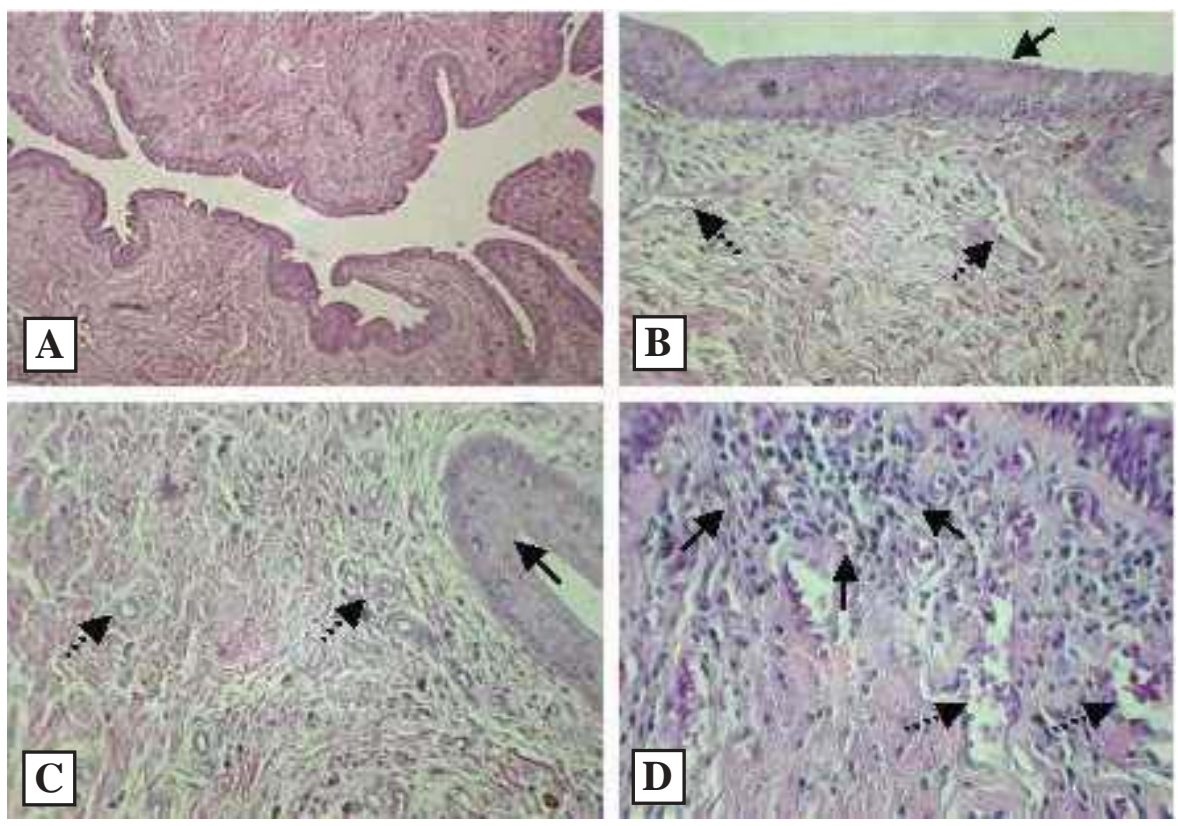

FIGURA 3 - Uretra de cão após implantação de mucosa bucal aos 60 dias de pós-operatório. A visão geral da área do implante onde não se identifica resquícios da arquitetura da mucosa bucal, $\mathrm{HE}$ 125X. B e C - Epitélio de transição (setas contínuas) e área sub-epidérmica com presença de formações vasculares típicas de tecido de granulação (setas interrompidas), HE 250X. D - Área subepidérmica da área do enxerto com infiltrado linfoplasmocitário (seta contínua) e brotos vasculares preenchidos por hemácias (seta interrompida), HE 400X. 


\section{Discussão}

O extravasamento urinário pode provocar retardo na cicatrização uretral, com formação de fibrose e estenoses ${ }^{17}$. Fístulas uretro-cutâneas de duração média de vinte dias foram observadas em seis animais e provavelmente a causa destas complicações possa ser atribuída a falta da derivação urinária no pós-operatório. No homem, o procedimento mais comumente recomendado é a drenagem supra-púbica na qual um catéter de cistotomia é mantido na uretra até a cicatrização da ferida ${ }^{2,9,15}$. Embora este seja considerado um método apropriado para o homem, sua adoção para o cão neste experimento seria questionável, pois ainda que as gaiolas fossem higienizadas diariamente, é praticamente impossível manter as condições sanitárias essenciais para evitar a contaminação ascendente do trato urinário. Em estudo feito em caprinos machos submetidos à marsupialização vesical, pode-se observar o desenvolvimento de cistite supurativa, o que permitiu aos autores concluir que a limpeza do ambiente bem como do abdômen do animal, deve ser considerada primordial para o impedimento da instalação de infecção no sítio de drenagem vesical ${ }^{18}$. A cistite observada em todos os animais pode ser atribuída à permanência intravesical do cateter, o que é sustentado por relatos que afirmam que o cateterismo vesical está entre os fatores que podem promover infecção do trato urinário ${ }^{19}$. Thomas ${ }^{20}$ afirmou que tal afecção está relacionada ao equilíbrio entre os mecanismos de defesa do hospedeiro e os microrganismos introduzidos. $\mathrm{O}$ autor ressaltou que a parede vesical resiste ou erradica a infecção graças a vários mecanismos intrínsecos, pois existe um componente secretório, provavelmente IgA, na mucosa vesical, que evitaria a aderência de microrganismos sobre a mucosa, permitindo assim a sua eliminação através da esfoliação epitelial vesical. Bactérias que tenham permanecido podem penetrar na parede da bexiga através de superfícies ulceradas.
Trabalhos desenvolvidos no homem sugerem que uretroplastias em retalho apresentam melhores resultados do que as tubulares no tocante ao desenvolvimento de estenoses e saculações ${ }^{12}$. Para minimizar a ocorrência desta última complicação, que acomete na maioria das vezes a superfície ventral, propõe-se a perfeita aposição do implante sobre o corpo cavernoso do pênis. Falhas nesta etapa do procedimento podem levar a mobilização do implante bem como a perda de sua viabilidade $^{2}$. Mesmo com o conhecimento da possibilidade do desenvolvimento de saculações, propôs-se no presente estudo, a reconstrução da superfície ventral da uretra com o propósito de reversão de uretrostomia no cão, uma vez que tal procedimento pode resultar no aumento da predisposição às infecções vesicais, comprometendo o prognóstico a longo prazo.

\section{Conclusão}

Com base nos resultados obtidos neste trabalho pode-se concluir que o implante em retalho ventral, com fragmentos de mucosa bucal autógena é adequado para correção de defeito uretral produzido por uretrostomia no cão embora possa ocorrer a formação de saculações no sítio do selamento.

\section{Referências}

1. Kröpfl D, Tucak A, Prlic D, et al. Using buccal mucosa for urethral reconstruction in primary and re-operative surgery. Ped urol 1998; 34: 216-20.

2. Pansadoro V, Emmiliozzi P, Gaffi M, et al. Buccal mucosa urethroplasty for the treatment of bulbar urethral strictures. J Urol 1999; 161: 1501-3.

3. Lopez JA, Valle J, Timon A, et al. Use of autologous buccal mucosal graft for urethral surgery in males. Eur Urol 1996; 29: 227 30 .

4. Andrich DE, Leach CJ, Mundy AR. The Barbagli procedure gives the best results for patch urethroplasty of the bulbar urethra Brit J Urol 2001; 88:385-9.
5. Pecheman JrRD. Urinary trauma in dogs and cats: a review. J Am An Hosp Assoc 1982; 18: 33-6.

6. Fossum TW, Hedlund CS, Hulse DA, et al Cirurgia de Pequenos Animais 1ed. São Paulo: Editora Roca; 2002, p. 533-70.

7. Archibald J, Owen R. Urinary sistem, In: Archibald J:.Canine Surgery. California: AVP- 1974. p. 629-701.

8. Osborne CA. Infecções bacterianas do trato urinário canino e felino: causa, cura e controle, In Bojrab JM. Mecanismos da Moléstia na Cirurgia de Pequenos Animais. São Paulo: Editora Manole, 1996. p. 50242.

9. Watanabe K, Okawa A, Kiyono M. Reconstruction of the urethral meatus with a buccal mucosa graft. Urol 1995;55:29-31.

10. Eppley BL, Keating M, Rink R. A buccal mucosal harvesting technique for urethral reconstruction. J Urol 1997; 157:1268-70.

11. Yerks EB, Adams MC, Miller DA et al. Coronal cuff: a problem site for buccal mucosal grafts. J Urol 1999; 162: 1442-4.

12. Holland AJA, Smith GHH. Effect of the depht and width of the urethral plate on tubularizad incised plate urethroplasty. J Urol 2000; 164: 489-91.

13. Monfort G, Di Benedetto V, Meyrat BJ. Sténoses urétrales chez l'enfant: traitment par urétroplastie avec greffon de muqueuse vésicale ou bucale. Ann. Fano 1993; 27 : 237-42.

14. Barbagli G, Palminteri E, Rizzo M. Dorsal onlay graft uretroplaty using penile skin or buccal mucosa in adult bulbourethral strictures. J Urol 1998; 160:1307-9.

15. Caldamone AA, Edstrom LE, Koyle MA, et al. Buccal mucosal grafts for urethral reconstruction. Urol 1998; 51: 15-9.

16. Cobea - Principios éticos na experimentação animal in Cobea, legislação e ética, s.d. disponível em http://www.meusite.com.br/ COBEA/etica.htm\#3.

17. Morey AF, McAninch JW. Technique of harvesting buccal mucosa for urethral reconstruction. J Urol 1996; 155:1696-7.

18. May KA, Moll HD, Duncan RB et al. Experimental evaluation of urinary bladder marsupialization in male goats. 2002; Vet Surg 31: 251-8.

19. Barsanti, JA, Blue J, Edmunds J. Urinary tract infection due indwelling bladder catheters in dogs and cats. J Am Vet Med Assoc 1985; 15: 384-8.

20. Thomas JE. Urinary tract infection induced by intermitent urethral catheterization in dogs. J Am Vet Med Assoc 1979; 174: 705-7. 
Paulo NM, Silva FF, Brito GA, Damasceno AD, Brito LAB, Freitas JS, Neves PL, Akinaga MH, Barbosa LM, Vêncio CM. Urethral reconstruction with autogenous buccal mucosa graft following urethrostomy in dogs. Acta Cir Bras [serial online] 2004 Mar-Apr;19(2). Available from URL: http://www.scielo.br/acb.

ABSTRACT - Purpose: To verify if the buccal mucosa autogen would be suitable for urethral reconstruction in a presence of fibrous tissue and if the procedures could determine the formation of fistulas and saculation at the receptor sites. Methods: Seven adult dogs was subjected to pre-escrotal uretrostomy. After 40 days, the urethrostomy was corrected through the inplantation of the buccal mucosa fragments at ventral wall of the urethra. The dogs were observed during 40 days, when, it were subjected to radiografic examination and slaughtered to histological study. Results: All animals showed cystitis and urethrocutaneous fistula in average time of 20 days. The radiografic aspects at 40 days showed: luminal continuity in seven animals and saculations at ventral wall of the urethra in six dogs, without interference in urinary jet quality. The histologic findings indicate the complete integration of the buccal mucosa to receiver site. Conclusion: The graft implanted at ventral wall, employing autogen buccal mucosa is suitable to correction of the urethral defects produced by urethrostomy in dogs, although saculations on receiver site can happen.

KEY WORDS - Dogs. Mouth mucosa. Transplantation, homologous. Urethra.

Conflito de interesse: nenhum Fonte de financiamento: nenhuma

\author{
Correspondência \\ Neusa Margarida Paulo \\ Universidade Federal de Goiás - Campus Samambaia \\ Escola de Veterinária \\ 74001-970 Goiânia-GO \\ nmp@ vet.ufg.br
}

Data do recebimento: 20/12/2003

Data da revisão: $15 / 01 / 2004$

*Fotos coloridas disponíveis em www.scielo.br/acb

Data da aprovação: 02/02/2004 